\title{
Safety of a 13-Valent Pneumococcal Conjugate Vaccine in EIderly Adults Previously Immunized with a 23-Valent Pneumococcal Polysaccharide Vaccine: An Open-Label Trial
}

\author{
Tino F. Schwarz ${ }^{*}$, Karlis Pauksens ${ }^{2}$, Christine Juergens ${ }^{3}$, Deepthi Jayawardene ${ }^{4}$, Daniel A. Scott ${ }^{5}$, \\ William C. Gruber ${ }^{5}$, Beate Schmoele-Thoma ${ }^{3}$ \\ ${ }^{1}$ Central Laboratory and Vaccination Centre, Stiftung Juliusspital, Würzburg, Germany; ${ }^{2}$ Department of Medical Sciences, Section of \\ Infectious Diseases, Uppsala University, Akademiska Sjukhuset, Uppsala, Sweden; ${ }^{3}$ Pfizer Pharma GmbH, Berlin, Germany; ${ }^{4}$ Pfizer \\ Inc., Collegeville, USA; ${ }^{5}$ Pfizer Vaccine Research, Pfizer, Pearl River, USA. \\ Email: "t.schwarz@juliusspital.de
}

Received July $25^{\text {th }}, 2013$; revised August $31^{\text {st }}, 2013$; accepted September $23^{\text {rd }}, 2013$

Copyright (C) 2013 Tino F. Schwarz et al. This is an open access article distributed under the Creative Commons Attribution License, which permits unrestricted use, distribution, and reproduction in any medium, provided the original work is properly cited.

\begin{abstract}
An open-label, multicenter study was conducted to describe the safety of the 13-valent pneumococcal conjugate vaccine (PCV13) in 1049 individuals aged $\geq 68$ years, who had previously been immunized with the unconjugated 23-valent pneumococcal polysaccharide vaccine (PPSV23). In addition, the safety profile of PCV13 in this study was compared, in a post-hoc descriptive analysis, to that observed in other elderly populations, who had received PCV13 or PPSV23 as part of other completed studies. Local (56.6\%) and systemic reactions (58.4\%) were very common, but were mainly mild, and of short duration (mean: 1.3 - 4.6 days). There were no related serious adverse events (AEs) within 1 month after PCV13. 123 days after PCV13 and 94 days after a nonstudy influenza vaccine, a case of transient Guillain-Barré syndrome occurred, which the investigator assessed as possibly related to the vaccination. Reactogenicity observed in this study population was generally similar to that of other elderly study populations with PPSV23-preimmunized adults, and with PPSV23-naïve adults. Reactogenicity was less common in this study than that observed in PPSV23-preimmunized adults who were revaccinated with PPSV23 rather than a subsequent dose of PCV13. There were no related serious AEs reported after PCV13 and PPSV23 in these comparator studies. Conclusion: PCV13 may be administered safely to older adults previously immunized with PPSV23. (ClinicalTrials. gov Identifier: NCT00500266)
\end{abstract}

Keywords: 13-Valent Pneumococcal Conjugate Vaccine; 23-Valent Pneumococcal Polysaccharide Vaccine; Streptococcus pneumoniae; Reactogenicity; Safety

\section{Introduction}

Diseases caused by Streptococcus pneumoniae remain important causes of morbidity and mortality in older adults [1]. This is despite the availability of an unconjugated 23-valent pneumococcal polysaccharide vaccine (PPSV23) introduced in 1983, and the indirect effects on disease burden following the introduction of pneumococcal conjugate vaccines (PCV) for children over the last decade. PCV vaccines have the ability to reduce nasopharyngeal colonization and subsequent disease trans-

*Corresponding author. mission of vaccine-type pneumococcal strains (herd effect) to older age groups [2].

PPSV23, an unconjugated, T-cell-independent, free-polysaccharide pneumococcal vaccine, is efficacious against invasive pneumococcal disease (IPD); however, reports on efficacy against community-acquired pneumonia (CAP) have been inconsistent $[3,4]$. The duration of protection is limited to about 3 - 5 years $[4,5]$, and revaccination is not generally recommended with the exception of certain immunocompromised populations who are at increased risk of IPD [6]. Studies have shown that a subsequent vaccination with PPSV23 may result in 
an immune response that is reduced in comparison with that achieved after the initial vaccination. However, the clinical significance of this is unknown [7-9].

A 13-valent pneumococcal conjugate vaccine (PCV13) was introduced for adults aged $\geq 50$ years in 2011 . PCV13 is manufactured by conjugating the capsular saccharides of $S$. pneumoniae to an immunogenic protein carrier $\left(\mathrm{CRM}_{197}\right)$ in order to elicit a T-cell-dependent immune response. $T$ cells provide the signals required for the generation of B-cell memory [10]. PCV13 has thus the potential for eliciting a memory response with rapid mobilization of antibody-forming cells on subsequent natural exposure, and permitting revaccination, if required.

This study was conducted to collect additional safety information to support licensing of PCV13 when administered to an elderly population aged $\geq 68$ years who had previously been immunized with PPSV23. In addition, the safety findings from this study (study 3000) were compared in a post-hoc descriptive analysis with those of two other PCV13 studies with adult populations. The comparator studies included one study (study 3005) which enrolled a PPSV23-preimmunized population aged $\geq 70$ years [11] and a second study (study 3008 ) which enrolled a population aged $\geq 65$ years not previously immunized with PPSV23 (PPSV23-naïve) [12]. All studies were part of the adult clinical development program for licensing PCV13.

\section{Methods}

\subsection{Study Design}

This was an open-label, single-arm trial conducted at 68 sites in the USA, Germany, and Sweden from 27 May 2008 to 16 April 2009 in accordance with the ethical principles of the Declaration of Helsinki. Informed consent was signed by all participants before study enrollment.

\subsection{Participants}

Participants included healthy adults aged $\geq 68$ years who had received one or more doses of PPSV23 at least 3 years previously and who were able to complete a handheld electronic diary (e-diary). Adults with underlying diseases that were stable for 6 or more weeks prior to vaccination were included. Participants were ineligible if they had a history of a severe vaccine reaction; received a diphtheria-containing vaccine within the past 6 months; had documented S. pneumoniae infection within the past 5 years; had an immunodeficiency or immunosuppression; had a severe chronic disorder with renal, cardiac, or pulmonary failure, or received any blood products or immunoglobulins within the past 6 months; were on anticoagulant therapy or had any other contraindication to intramuscular injection; had severe cognitive impairment; or were residents of a long-term care facility.

\subsection{Data Collection}

The participants recorded local and systemic reactions on an e-diary in the evening for 14 days after vaccination. The e-diary prompted reporting of vaccine-associated signs and symptoms via a checklist within a fixed time window, providing an accurate representation of each participant's experience. Severity was assessed using the US Food and Drug Administration's "Toxicity Grading Scale" [13]. The largest diameter of any redness or swellling was measured using a caliper. Oral temperature was measured using a digital thermometer, and fever was defined as a temperature of $\geq 38.0^{\circ} \mathrm{C}\left(100.4^{\circ} \mathrm{F}\right)$. The highest daily temperature was recorded. Diary data were transmitted by the participants to the central vendor and thereafter could not be altered. The data were reviewed on an ongoing basis by the investigator and the sponsor, via an internet-based portal, to monitor vaccine reactogenicity and compliance with e-diary completion.

Other adverse events (AEs), including pain at the injection site within 30 minutes of vaccination, and other unanticipated events not prompted by the e-diary, were collected by the investigator on the electronic $\mathrm{AE}$ case report form from the signing of the informed consent form until the next visit approximately 1 month after vaccination. There was also a 6-month follow-up phone call to collect any newly diagnosed chronic medical conditions and serious AEs (SAEs) since the last visit. AE collection by the investigator was based on the participants' responses to nonspecific questions.

\subsection{Interventions}

PCV13 contains pneumococcal capsular polysaccharides of serotypes 1, 3, 4, 5, 6A, 6B, 7F, 9V, 14, 18C, 19A, $19 \mathrm{~F}$, and $23 \mathrm{~F}$ (containing $2.2 \mu \mathrm{g}$ of each saccharide, except for $4.4 \mu \mathrm{g}$ of $6 \mathrm{~B}$ ) individually conjugated to nontoxic diphtheria toxoid cross-reacting material 197 $\left(\mathrm{CRM}_{197}\right), 0.85 \%$ sodium chloride, $0.02 \%$ polysorbate 80 , and $0.125 \mathrm{mg}$ aluminum phosphate per $0.5 \mathrm{~mL}$ dose. PCV13 was manufactured by Wyeth, a Pfizer Company (lot number 7-5095-005A). A single dose of PCV13 $(0.5 \mathrm{~mL})$ was administered by intramuscular injection into the deltoid muscle of either arm. Needle length was not specified and was left to the judgment of the investigator to choose the optimal needle length to ensure intramuscular delivery.

\subsection{Sample Size}

For the sample size calculation, an incidence rate of reactogenicity and AEs of at least $0.3 \%$, a type I error rate 
of 0.05 , and a dropout rate of no more than $5 \%$ were assumed. A sample size of 1000 evaluable participants would provide no more than a $5 \%$ chance of missing an event when the frequency of the event is at least 3 in 1000 participants. Assuming a dropout rate of $\leq 5 \%$, an overall sample size of approximately 1053 enrolled participants would achieve 1000 evaluable participants for this study.

\subsection{Safety Analysis}

The incidences of local and systemic reactions, including use of antipyretic and pain medications, and other AEs were summarized using descriptive statistics. AEs were categorized according to the Medical Dictionary for Regulatory Activities (MedDRA).

\subsection{Comparison with Other PCV13 Studies}

Two other studies in the PCV13 clinical development program had enrolled subjects of similar age groups. One study (study 3005 ) assessed the safety and immunogenicity of PCV13 compared with PPSV 23 in a PPSV23-preimmunized population aged $\geq 70$ years who had received PPSV23 at least 5 years prior [11]; the other study (study 3008) evaluated the safety and immunogenicity of PCV13 when administered concomitantly with the trivalent inactivated influenza vaccine (TIV), compared with PCV13 given alone 1 month after TIV, in a population aged $\geq 65$ years who were PPSV23-naïve [12]. Apart from PPSV23 preimmunization status, inclusion and exclusion criteria for the study populations and data collection of local and systemic reactions and AEs were similar between the present study and the compara- tor studies.

The PCV13 safety data from study 3000 were compared with the PCV13 and PPSV23 data from study 3005 [11], and with the PCV13 data from the vaccine group who received PCV13 alone 1 month after TIV and placebo in study 3008 [12]. The incidences of local and systemic reactions, and AEs were compared using descriptive statistics.

\section{Results}

\subsection{Study Population}

A total of 1077 participants consented, of which 28 were not eligible for the study. Of the 1049 PCV13 recipients, nine withdrew (three participant requests, three deaths, and three lost to follow-up); 1040 participants completed the study. Participants' demographic characteristics are presented under study 3000 in Table 1. The most commonly reported comorbidities in this population included hypertension $(69.2 \%)$, osteoarthritis $(42.2 \%)$, hypercholesterolemia $(30.1 \%)$, hyperlipidemia $(26.8 \%)$, gastroesophageal reflux disease (27.4\%), drug hypersensitivity $(29.5 \%)$, cataract $(15.9 \%)$, coronary artery disease (12.8\%), chronic obstructive pulmonary disease $(13.3 \%)$, asthma (12.6\%), and bronchitis (8.1\%).

\subsection{Local and Systemic Reactions}

A total of $96.1 \%$ of participants completed $\geq 75 \%$ of all days during the 14 days after vaccination; $60.3 \%$ of participants completed all 14 days of the e-diaries. The frequencies of e-diary-prompted events are summarized in Table 2. Most of the local reactions were mild and of

Table 1. Baseline demographic characteristics of the safety populations.

\begin{tabular}{|c|c|c|c|c|c|}
\hline \multirow{3}{*}{ Characteristic, $\%$} & & \multicolumn{3}{|c|}{ PPSV23-Preimmunized Adults } & \multirow{3}{*}{$\begin{array}{c}\text { PPSV23-Naïve Adults } \\
\text { Study } 3008[12] \\
\text { PCV13* }^{*}(\mathrm{n}=575)\end{array}$} \\
\hline & & \multirow{2}{*}{$\begin{array}{c}\text { Study } 3000 \\
\text { PCV13 } \\
(n=1049) \\
\end{array}$} & \multicolumn{2}{|c|}{ Study 3005 [11] } & \\
\hline & & & $\begin{array}{c}\text { PCV13 } \\
(n=463)\end{array}$ & $\begin{array}{l}\text { PPSV23 } \\
(n=473)\end{array}$ & \\
\hline \multirow{2}{*}{ Gender } & Females & $55.7 \%$ & $47.7 \%$ & $49.7 \%$ & $50.4 \%$ \\
\hline & Males & $44.3 \%$ & $52.3 \%$ & $50.3 \%$ & $49.6 \%$ \\
\hline \multirow{5}{*}{ Race } & White & $97.8 \%$ & $95.9 \%$ & $96.0 \%$ & $99.3 \%$ \\
\hline & Black/African American & $1.5 \%$ & $2.6 \%$ & $2.1 \%$ & $0.2 \%$ \\
\hline & Asian & $0.3 \%$ & $0.6 \%$ & $1.7 \%$ & $0.3 \%$ \\
\hline & American Indian/Alaska Native & $0.1 \%$ & $0.2 \%$ & $0.2 \%$ & - \\
\hline & Native Hawaiian/Other Pacific Islander & - & $0.2 \%$ & $0.0 \%$ & - \\
\hline \multicolumn{2}{|c|}{ Mean age in years (SD) } & $75.3(5.1)$ & $76.7(4.6)$ & $76.7(4.5)$ & $72.1(5.5)$ \\
\hline
\end{tabular}

PCV13 = 13-valent pneumococcal conjugate vaccine; PPSV23 $=23$-valent pneumococcal polysaccharide vaccine; $\mathrm{SD}=$ standard deviation. ${ }^{*}=\mathrm{PCV} 13$ recipients in study 3008 who received PCV13 1 month after trivalent inactivated influenza vaccine (TIV) and placebo. 
Table 2. Local and systemic reactions within 14 days after vaccination with PCV13 in PPSV23-preimmunized adults in the present study 3000 and in study 3005, and in PPSV23-naïve adults in study 3008.

\begin{tabular}{|c|c|c|c|c|c|c|}
\hline & & \multicolumn{4}{|c|}{ PPSV23-Preimmunized Adults } & \multirow{2}{*}{$\begin{array}{c}\begin{array}{c}\text { PPSV23-Naïve } \\
\text { Adults }\end{array} \\
\text { Study } 3008[12]\end{array}$} \\
\hline \multirow{2}{*}{\multicolumn{2}{|c|}{ Local Reactions, \% }} & Study 3000 & & Study 3005 [11] & & \\
\hline & & $\geq 68$ years & & $\geq 70$ years & & $\geq 65$ years \\
\hline & & $\begin{array}{c}\text { PCV13 } \\
\left(n^{*}=664-777\right)\end{array}$ & $\begin{array}{c}\text { PCV13 } \\
\left(n^{*}=306-362\right)\end{array}$ & $\begin{array}{c}\text { PPSV23 } \\
\left(\mathrm{n}^{*}=324-383\right)\end{array}$ & p-Value ${ }^{* *}$ & $\begin{array}{c}\text { PCV13 } \\
\left(n^{*}=420-470\right)\end{array}$ \\
\hline \multirow{4}{*}{ Redness $^{* * *}$} & Any & $14.3 \%$ & $10.8 \%$ & $22.2 \%$ & $<0.001$ & $12.3 \%$ \\
\hline & Mild & $12.6 \%$ & $9.5 \%$ & $13.5 \%$ & 0.129 & $9.7 \%$ \\
\hline & Moderate & $6.5 \%$ & $4.7 \%$ & $11.5 \%$ & 0.002 & $6.1 \%$ \\
\hline & Severe & $1.1 \%$ & $1.7 \%$ & $4.8 \%$ & 0.028 & $1.0 \%$ \\
\hline \multirow{4}{*}{ Swelling ${ }^{* * *}$} & Any & $12.8 \%$ & $10.4 \%$ & $23.1 \%$ & $<0.001$ & $10.2 \%$ \\
\hline & Mild & $10.9 \%$ & $8.9 \%$ & $14.0 \%$ & 0.048 & $8.1 \%$ \\
\hline & Moderate & $5.5 \%$ & $4.0 \%$ & $13.6 \%$ & $<0.001$ & $5.0 \%$ \\
\hline & Severe & $0.6 \%$ & $0.0 \%$ & $4.8 \%$ & $<0.001$ & $0.0 \%$ \\
\hline \multirow{4}{*}{ Pain $^{\dagger}$} & Any & $51.0 \%$ & $51.7 \%$ & $58.5 \%$ & 0.062 & $43.4 \%$ \\
\hline & Mild & $49.4 \%$ & $50.1 \%$ & $54.1 \%$ & 0.284 & $37.9 \%$ \\
\hline & Moderate & $9.0 \%$ & $7.5 \%$ & $23.6 \%$ & $<0.001$ & $19.7 \%$ \\
\hline & Severe & $0.2 \%$ & $1.3 \%$ & $2.3 \%$ & 0.539 & $2.6 \%$ \\
\hline \multirow{4}{*}{$\begin{array}{l}\text { Limitation of arm } \\
\text { movement }\end{array}$} & Any & $16.2 \%$ & $10.5 \%$ & $27.6 \%$ & $<0.001$ & $14.8 \%$ \\
\hline & Mild & $14.8 \%$ & $10.3 \%$ & $25.2 \%$ & $<0.001$ & $13.4 \%$ \\
\hline & Moderate & $1.6 \%$ & $0.3 \%$ & $2.6 \%$ & 0.020 & $1.0 \%$ \\
\hline & Severe & $1.6 \%$ & $0.7 \%$ & $3.0 \%$ & 0.042 & $1.4 \%$ \\
\hline \multicolumn{2}{|c|}{ Systemic Reactions, \% } & $\left(n^{*}=634-733\right)$ & $\left(n^{*}=299-350\right)$ & $\left(n^{*}=301-367\right)$ & p-Value ${ }^{* *}$ & $\left(n^{*}=419-456\right)$ \\
\hline \multirow{4}{*}{ Fever $^{\S}$} & Any & $1.1 \%$ & $1.0 \%$ & $2.3 \%$ & 0.253 & $3.6 \%$ \\
\hline & Mild & $0.8 \%$ & $1.0 \%$ & $2.0 \%$ & 0.535 & $3.1 \%$ \\
\hline & Moderate & $0.0 \%$ & $0.0 \%$ & $0.0 \%$ & $>0.999$ & $1.0 \%$ \\
\hline & Severe & $0.3 \%$ & $0.0 \%$ & $0.3 \%$ & 0.509 & $0.0 \%$ \\
\hline \multicolumn{2}{|c|}{ Fatigue } & $34.4 \%$ & $34.0 \%$ & $43.3 \%$ & 0.011 & $28.5 \%$ \\
\hline \multicolumn{2}{|c|}{ Headache } & $26.1 \%$ & $23.7 \%$ & $26.0 \%$ & 0.510 & $24.7 \%$ \\
\hline \multicolumn{2}{|c|}{ Chills } & $7.5 \%$ & $7.9 \%$ & $11.2 \%$ & 0.162 & $9.1 \%$ \\
\hline \multicolumn{2}{|c|}{ Rash } & $8.4 \%$ & $7.3 \%$ & $16.4 \%$ & $<0.001$ & $6.8 \%$ \\
\hline \multicolumn{2}{|c|}{ Decreased appetite } & $11.2 \%$ & $10.4 \%$ & $11.5 \%$ & 0.688 & $11.3 \%$ \\
\hline \multicolumn{2}{|c|}{ Vomiting } & $0.9 \%$ & $1.7 \%$ & $1.3 \%$ & 0.808 & $1.7 \%$ \\
\hline \multicolumn{2}{|c|}{ Diarrhea } & $14.5 \%$ & - & - & - & - \\
\hline \multicolumn{2}{|c|}{ New muscle pain } & $25.3 \%$ & $36.8 \%$ & $44.7 \%$ & 0.034 & $23.4 \%$ \\
\hline \multicolumn{2}{|c|}{ Aggravated muscle pain } & $12.3 \%$ & $20.6 \%$ & $27.5 \%$ & 0.039 & $15.0 \%$ \\
\hline \multicolumn{2}{|c|}{ New joint pain } & $12.8 \%$ & $12.6 \%$ & $14.9 \%$ & 0.413 & $11.5 \%$ \\
\hline \multicolumn{2}{|c|}{ Aggravated joint pain } & $9.7 \%$ & $11.6 \%$ & $16.5 \%$ & 0.081 & $8.6 \%$ \\
\hline
\end{tabular}

PCV13 = 13-valent pneumococcal conjugate vaccine; PPSV23 = 23-valent pneumococcal polysaccharide vaccine. ${ }^{*} \mathrm{n}=$ number of participants with known values. ${ }^{* *}$ p-Value (based on procedure of Chan \& Zhang [14]) for the difference in proportions, expressed as a percentage [PCV13] - [PPSV23]. ${ }^{* * *}$ Severity of redness and swelling was categorized as absent (if none or minimal: 0 to $<2.5 \mathrm{~cm}$ ), mild $(2.5$ to $5.0 \mathrm{~cm})$, moderate $(5.1$ to $10.0 \mathrm{~cm})$, or severe $(>10.0 \mathrm{~cm})$. ${ }^{\dagger}$ Severity of pain was categorized as mild (no interference with activity), moderate (some interference with activity), or severe (prevents routine daily activity). ${ }^{\dagger}$ Limitation of arm movement was categorized as mild (some limitation of arm movement), moderate (unable to move arm above head but able to move arm above shoulder), or severe (unable to move arm above shoulder). ${ }^{\S} \mathrm{Fever}$ was graded as any $\left(\geq 38^{\circ} \mathrm{C}\left[\geq 100.4^{\circ} \mathrm{F}\right]\right)$, mild $\left(\geq 38^{\circ} \mathrm{C}\left[\geq 100.4^{\circ} \mathrm{F}\right]\right.$ but $<38.5^{\circ} \mathrm{C}$ $\left.\left[<101.2^{\circ} \mathrm{F}\right]\right)$, moderate $\left(\geq 38.5^{\circ} \mathrm{C}\left[\geq 101.2^{\circ} \mathrm{F}\right]\right.$ but $\left.<39^{\circ} \mathrm{C}\left[<102.1^{\circ} \mathrm{F}\right]\right)$, or severe $\left(\geq 39^{\circ} \mathrm{C}\left[\geq 102.1^{\circ} \mathrm{F}\right]\right.$ but $\left.\leq 40^{\circ} \mathrm{C}\left[\leq 104.0^{\circ} \mathrm{F}\right]\right)$. No fever $>40^{\circ} \mathrm{C}\left[>104.0^{\circ} \mathrm{F}\right]$ occurred in any study. 
short duration (mean duration 2.1 - 4.1 days). One or more severe local reactions were reported in 17 participants $(2.6 \%)$ : eight had severe limitation of arm movement only; four had severe redness only; two had severe redness and swelling; one had severe limitation of arm movement, redness, and swelling; one had severe swelling only; and one had severe injection-site pain and limitation of arm movement. The systemic reactions were also of short duration (mean duration 1.3 - 4.6 days); the most frequently reported were fatigue, headache, and muscle pain. A total of $17.0 \%$ of participants reported use of pain medication and $6.4 \%$ reported use of fever medication.

\subsection{Other Adverse Events within 1 Month after PCV13 Administration}

Pain at the injection site within 30 minutes after vaccination occurred in $4.5 \%(n=47)$ of participants and was mainly mild (4.1\%). Other AEs (179 events) occurred in $12.1 \%(\mathrm{n}=127)$ of participants; the most frequently reported were diarrhea, nausea, bronchitis, arthralgia, and myalgia, each occurring in $0.6 \%(n=6)$ of participants. A total of 19 AEs in $16(1.5 \%)$ participants were judged by the investigator as possibly related to PCV13; of these 19 AEs, injection-site pain $(\mathrm{n}=2)$ and myalgia $(\mathrm{n}=2)$ were most common. Of all AEs, 11 were serious; they occurred in $10(1.0 \%)$ participants and included bradyarrhythmia, tachyarrhythmia, gastritis, small intestine obstruction, appendicitis, basal cell carcinoma $(n=2)$, loss of consciousness, hip fracture, skin burning sensation, and peripheral arterial occlusive disease, but were assessed by the investigator as not related to PCV13.

\subsection{Other Adverse Events during the 6-Month Follow-Up Period}

At the 6-month follow-up phone call, 10.2\% $(n=107)$ of participants had newly diagnosed chronic medical conditions and SAEs (173 events): osteoarthritis $(0.6 \%, \mathrm{n}=6)$; chronic obstructive pulmonary disease $(0.6 \%, \mathrm{n}=6)$; pneumonia $(0.4 \%, \mathrm{n}=4)$; and arthralgia $(0.4 \%, \mathrm{n}=4)$ were most commonly observed. Of these AEs, 41 (3.9\%) participants had 67 events that were serious; neoplasms $(1.1 \% ; \mathrm{n}=12)$ and cardiac disorders $(1.0 \% ; \mathrm{n}=11)$ were the most common. Three SAEs resulted in death and included metastatic adenocarcinoma; non-small cell lung cancer; and septic shock in a participant with underlying lung fibrosis, Klebsiella pneumoniae, and respiratory failure.

Two participants reported AEs judged by the investigator as being possibly related to PCV13. One participant who reported paresthesia of the finger tips on day 16 and myalgia on day 32 also reported, in the follow-up period, arthralgia on day 106, bursitis and tendonitis in the right shoulder on day 142 , and bursitis in the right hip on day 142. The other participant developed Guillain-Barré syndrome (GBS) 123 days after PCV13 and 94 days after administration of a nonstudy influenza vaccine. This participant also had eczema over the scapula area; a Varicella zoster infection was suspected but the diagnosis was not confirmed.

\subsection{Comparison with Other PCV13 Studies}

The demographic characteristics of the comparator studies with PPSV23-preimmunized participants (study 3005) and PPSV23-naïve participants (study 3008) are shown in Table 1. Mean age was generally similar across studies (range: 72.1 - 76.7 years). On comparing the two PPSV23-preimmunized study populations (the present study 3000 and study 3005 ) who received one study dose of PCV13, the reactogenicity of PCV13 was generally similar, with the exception of muscle pain, which was more common in study 3005 (Table 2).

In study 3005 there was a comparator arm in which participants received a study dose of PPSV23, in which allowed reactogenicity to be compared between PPSV23-preimmunized participants vaccinated with PCV13 and those (re) vaccinated with PPSV23; here redness, swelling, limitation of arm movement, fatigue, rash, and new and aggravated muscle pain were statistically significantly more common $(\mathrm{p}<0.05)$ after $(\mathrm{re})$ administration of PPSV23 than after administration of PCV13 (Table 2). When the present study population was compared with this PPSV23-comparator group in study 3005 , again the majority of local and systemic reactions were more common in participants who were (re) vaccinated with PPSV23 in study 3005 than in those vaccinated with a subsequent dose of PCV13 in study 3000 (Table 2).

On comparing the PPSV23-naïve study population (study 3008) with the present PPSV23-preimmunized study population (study 3000), the reactogenicity of PCV13 was similar across studies; exceptions were injection-site pain and fatigue, which were more common in the preimmunized study population of study 3000 (Table 2). Generally similar findings were observed on comparison of study 3008 with study 3005; here, injection-site pain, fatigue, and new and aggravated muscle pain were more common in the preimmunized study population of study 3005 than in the PPSV23-naïve population of study 3008 .

Other AEs reported in the comparator studies 3005 $(14.9 \%)$ and $3008(15.8 \%)$ were generally similar to those observed in the present study (12.1\%); but there were no vaccine-related SAEs after these study vaccinations in the comparator studies (data not shown). Information on AEs for each study is available elsewhere [11,12,15-17]. 


\section{Discussion}

As PPSV23 was introduced in 1983 and is generally recommended for adults aged $\geq 65$ years, there exists an elderly population who may have received PPSV23. As the period of protection of PPSV23 is limited to $3-5$ years, this population may require revaccination $[4,5]$. For this reason, the safety of PCV13 was assessed in adults aged $\geq 68$ years who had received PPSV23 at least 3 years earlier as part of the PCV13 clinical development program. Reactogenicity was collected using an e-diary. Reactogenicity data are considered possibly related to the vaccination due to the temporal association between the event and the vaccination. Compliance for e-diary completion was high, with only a small percentage not completing $\geq 75 \%$ of the 14-day assessments. Overall, e-diary-prompted events were mostly mild and of short duration. Fever $\left(\geq 38^{\circ} \mathrm{C}\left[\geq 100.4^{\circ} \mathrm{F}\right]\right)$, which is commonly seen in children after vaccination, was less common in this elderly population $(1.1 \%)$. The most commonly reported events were injection-site pain, fatigue, headache, and muscle pain. Severe local reactions were uncommon and observed in $<2 \%$ of participants.

One possibly related SAE occurred in this study. A 78-year-old female participant developed transient GBS at 123 days after PCV13 and 94 days after a nonstudy influenza vaccination. This participant also had a suspected Varicella zoster infection, although the diagnosis was not confirmed. GBS is commonly temporally associated with infections, such as Campylobacter jejuni, cytomegalovirus, Epstein-Barr virus, Mycoplasma pneumoniae, and Haemophilus influenzae [18]. Lasky et al. reported that 6 to 8 weeks after influenza vaccination, one per million persons may develop GBS [19]. Reports of an association between a meningococcal conjugate vaccine and GBS remain unconfirmed [20,21]. A recent publication on a retrospective study of data from 1994 to 2006 from the Kaiser Permanente of Northern California (KPNC) health care delivery system reported no evidence of an increased risk of GBS following vaccination of any kind [22].

One limitation of this safety study was its size, which cannot reliably detect an increased incidence of rare AEs. Another was the lack of direct comparison with PPSV23, a licensed vaccine with an acceptable safety profile $[23,24]$. However, direct comparison data are available from other studies $[9,11,25]$. The safety profile of PCV13 observed in the present study with PPSV23-preimmunized participants was similar to the safety profile observed in other PCV13 studies with PPSV23-preimmunized and PPSV23-naïve participants of similar ages for the majority of events; exceptions were injection-site pain, fatigue, and muscle pain (study 3005 only), which were generally more common in the PPSV23-preim- munized study populations [11,12]. PCV13 was generally less reactogenic in the present PPSV23-preimmunized study population when compared with a similar PPSV23-preimmunized study population (re) vaccinated with PPSV23 [11].

We concluded that PCV13 may be administered safely to older adults previously immunized with PPSV23.

\section{Acknowledgements}

This study was sponsored by Wyeth, which was acquired by Pfizer Inc in October 2009. The sponsor and all authors were involved in the study design and the data collection, analysis, and interpretation. The authors would like to thank James Trammel and colleagues at inVentiv Health Clinical for support with the data analyses. Medical writing support was provided by Nancy Price, PhD, at Excerpta Medica and was funded by Pfizer Inc.

\section{Conflict of Interest Statement}

C. J., D. J., D. A. S., W. C. G., and B. S. T. are all employees of Pfizer. T. F. S. has received honoraria from Pfizer, GlaxoSmithKline, and Novartis for conducting clinical trials and lecturing, and has participated as a member of advisory boards. K. P. has received honoraria from Pfizer, GlaxoSmithKline, and from Eurocine for conducting clinical trials. T. F. S. and K. P. did not receive honoraria from Pfizer for the development of this publication.

\section{REFERENCES}

[1] World Health Organization, "23-Valent Pneumococcal Polysaccharide Vaccine WHO Position Paper," Weekly Epidemiological Record, Vol. 83, No. 42, 2008, pp. 373384. http://www.who.int/wer/2008/wer8342.pdf

[2] K. Klugman, S. Black, R. Dagan, R. Malley and C. Whitney, "Pneumococcal Conjugate Vaccine and Pneumococcal Common Protein Vaccines," In: S. A. Plotkin and W. A. Orenstein, Eds., Vaccines, 6th Edition, Saunders, Philadelphia, 2012, pp. 534-535.

[3] A. Huss, P. Scott, A. E. Stuck, C. Trotter and M. Egger, "Efficacy of Pneumococcal Vaccination in Adults: A Meta-Analysis," Canadian Medical Association Journal, Vol. 180, No. 1, 2009, pp. 48-58. http://dx.doi.org/10.1503/cmaj.080734

[4] S. Moberley, J. Holden, D. P. Tatham and R. M. Andrews, "Vaccines for Preventing Pneumococcal Infection in Adults," Cochrane Database of Systematic Reviews, Vol. 23, No. 1, 2008, Article ID: CD000422. http://dx.doi.org/10.1002/14651858.CD000422.pub3

[5] Department of Health, UK, "JCVI Statement on the Routine Pneumococcal Vaccination Programme for Adults Aged 65 Years and Older (Updated 25 July 2011),"

http://webarchive.nationalarchives.gov.uk/201301071053 
54/http://www.dh.gov.uk/prod_consum_dh/groups/dh_dig italas-

sets/@dh/@ab/documents/digitalasset/dh 128704.pdf

[6] Centers for Disease Control and Prevention, Advisory Committee on Immunization Practices, "Updated Recommendations for Prevention of Invasive Pneumococcal Disease among Adults Using the 23-Valent Pneumococcal Polysaccharide Vaccine (PPSV23)," Morbidity and Mortality Weekly Report (MMWR), Vol. 59, No. 34, 2010, pp. 1102-1106.

http://www.cdc.gov/mmwr/preview/mmwrhtml/mm5934a 3.htm

[7] J. Torling, J. Hedlund, H. B. Konradsen and A. Ortqvist, "Revaccination with the 23-Valent Pneumococcal Polysaccharide Vaccine in Middle-Aged and Elderly Persons Previously Treated for Pneumonia," Vaccine, Vol. 22, No. 1, 2003, pp. 96-103. http://dx.doi.org/10.1016/S0264-410X(03)00521-8

[8] E. A. Clutterbuck, R. Lazarus, L. M. Yu, J. Bowman, E. A. Bateman, L. Diggle, et al., "Pneumococcal Conjugate and Plain Polysaccharide Vaccines Have Divergent Effects on Antigen-Specific B Cells," Journal of Infectious Diseases, Vol. 205, No. 9, 2012, pp. 1408-1416. http://dx.doi.org/10.1093/infdis/jis212

[9] L. A. Jackson, A. Gurtman, M. van Cleeff, R. W. Frenck, J. Treanor, K. U. Jansen, et al., "Influence of Initial Vaccination with 13-Valent Pneumococcal Conjugate Vaccine or 23-Valent Pneumococcal Polysaccharide Vaccine on Anti-Pneumococcal Responses Following Subsequent Pneumococcal Vaccination in Adults 50 Years and Older," Vaccine, Vol. 31, No. 35, 2013, pp. 3594-3602. http://dx.doi.org/10.1016/j.vaccine.2013.04.084

[10] G. Ada, "Vaccines and Vaccination," New England Journal of Medicine, Vol. 345, No. 14, 2001, pp. 1042-1053. http://dx.doi.org/10.1056/NEJMra011223

[11] L. A. Jackson, A. Gurtman, K. Rice, K. Pauksens, R. N. Greenberg, T. R. Jones, et al., "Immunogenicity and Safety of a 13-Valent Pneumococcal Conjugate Vaccine in Adults 70 Years of Age and Older Previously Vaccinated with 23-Valent Pneumococcal Polysaccharide Vaccine," Vaccine, Vol. 31, No. 35, 2013, pp. 3585-3593. http://dx.doi.org/10.1016/j.vaccine.2013.05.010

[12] T. F. Schwarz, J. Flamaing, H. C. Rumke, J. Penzes, C. Juergens, A. Wenz, et al., "A Randomized, Double-Blind Trial to Evaluate Immunogenicity and Safety of 13-Valent Pneumococcal Conjugate Vaccine Given Concomitantly with Trivalent Influenza Vaccine in Adults Aged $\geq$ 65 Years," Vaccine, Vol. 29, No. 32, 2011, pp. 5195- 5202. http://dx.doi.org/10.1016/j.vaccine.2011.05.031

[13] US Food and Drug Administration, "Guidance for Industry: Toxicity Grading Scale for Healthy Adult and Adolescent Volunteers Enrolled in Preventive Vaccine Clinical Trials," 2007.

http://www.fda.gov/BiologicsBloodVaccines/GuidanceCo mplianceRegulatoryInform-

tion/Guidances/Vaccines/ucm074775.htm

[14] I. S. Chan and Z. Zhang, "Test-Based Exact Confidence Intervals for the Difference of Two Binomial Proportions," Biometrics, Vol. 55, No. 4, 1999, pp. 1202-1209.
http://dx.doi.org/10.1111/j.0006-341X.1999.01202.x

[15] "Study Evaluating Safety of 13-Valent Pneumococcal Conjugate Vaccine in Healthy Elderly Subjects (Study 3000)," ClinicalTrials.gov Identifier: NCT00500266. http://clinicaltrials.gov/show/NCT00500266

[16] "Study Evaluating Safety, Tolerability and Immunogenicity of a 13-Valent Pneumococcal Conjugate Vaccine (Study 3005)," ClinicalTrials.gov Identifier: NCT00546572. http://clinicaltrials.gov/ct2/show/results/NCT00546572

[17] "Study Evaluating Safety and Immunogenicity of 13Valent Pneumococcal Conjugate Vaccine with Influenza Vaccine in Adults (Study 3008)," ClinicalTrials.gov Identifier: NCT00492557. http://clinicaltrials.gov/ct2/show/results/NCT00492557

[18] J. J. Sejvar, K. S. Kohl, J. Gidudu, A. Amato, N. Bakshi, R. Baxter, et al., "Guillain-Barré Syndrome and Fisher Syndrome: Case Definitions and Guidelines for Collection, Analysis, and Presentation of Immunization Safety Data," Vaccine, Vol. 29, No. 3, 2011, pp. 599-612. http://dx.doi.org/10.1016/j.vaccine.2010.06.003

[19] T. Lasky, G. J. Terracciano, L. Magder, C. L. Koski, M. Ballesteros, D. Nash, et al., "The Guillain-Barré Syndrome and the 1992-1993 and 1993-1994 Influenza Vaccines," New England Journal of Medicine, Vol. 339, No. 25, 1998, pp. 1797-1802. http://dx.doi.org/10.1056/NEJM199812173392501

[20] Centers for Disease Control and Prevention (CDC), "Update: Guillain-Barré Syndrome among Recipients of Menactra Meningococcal Conjugate Vaccine-United States, June 2005-September 2006," Morbidity and Mortality Weekly Report (MMWR), Vol. 55, No. 41, 2006, pp. 11201124.

http://www.cdc.gov/mmwr/preview/mmwrhtml/mm5541a 2.htm

[21] P. De Wals, G. Deceuninck, R. M. Boucher and M. Ouakki, "Risk of Guillain-Barré Syndrome Following Serogroup C Meningococcal Conjugate Vaccine in Quebec, Canada," Clinical Infectious Diseases, Vol. 46, No. 8, 2008, pp. E75-E77. http://dx.doi.org/10.1086/533469

[22] R. Baxter, N. Bakshi, B. Fireman, E. Lewis, P. Ray, C. Vellozzi, et al., "Lack of Association of Guillain-Barré Syndrome with Vaccinations," Clinical Infectious Diseases, Vol. 57, No. 2, 2013, pp. 197-204. http://dx.doi.org/10.1093/cid/cit222

[23] "Pneumovax 23-Pneumococcal Vaccine, Polyvalent," Merck \& Co., Inc, US Prescribing Information. http://www.fda.gov/BiologicsBloodVaccines/Vaccines/A pprovedProducts/ucm 179996.htm

[24] L. A. Jackson, "Pneumococcal Polysaccharide Vaccines," In: S. A. Plotkin and W. A. Orenstein, Eds., Vaccines, 6th Edition, Saunders, Philadelphia, 2012, pp. 542-572.

[25] L. A. Jackson, A. Gurtman, M. van Cleeff, K. U. Jansen, D. Jayawardene, C. Devlin, et al., "Immunogenicity and Safety of a 13-Valent Pneumococcal Conjugate Vaccine Compared to a 23-Valent Pneumococcal Polysaccharide Vaccine in Pneumococcal Vaccine-Naive Adults," Vaccine, Vol. 31, No. 35, 2013, pp. 3577-3584. http://dx.doi.org/10.1016/j.vaccine.2013.04.085 